\title{
Symptoms of social anxiety, depression and stress in parents of children with social anxiety disorder
}

Article

Accepted Version

Halldorsson, B., Draisey, J., Cooper, P. and Creswell, C. (2018) Symptoms of social anxiety, depression and stress in parents of children with social anxiety disorder. British Journal of Clinical Psychology, 57 (2). pp. 148-162. ISSN 0144-6657 doi: https://doi.org/10.1111/bjc.12170 Available at https://centaur.reading.ac.uk/74270/

It is advisable to refer to the publisher's version if you intend to cite from the work. See Guidance on citing.

To link to this article DOI: http://dx.doi.org/10.1111/bjc.12170

Publisher: British Psychological Society

All outputs in CentAUR are protected by Intellectual Property Rights law, including copyright law. Copyright and IPR is retained by the creators or other copyright holders. Terms and conditions for use of this material are defined in the End User Agreement.

www.reading.ac.uk/centaur 
Central Archive at the University of Reading

Reading's research outputs online 
Symptoms of social anxiety, depression and stress in parents of children with social anxiety disorder

Brynjar Halldorsson*, Jenny Draisey, Peter Cooper and Cathy Creswell School of Psychology and Clinical Language Sciences, University of Reading

*Address for correspondence:

Brynjar Halldorsson,

School of Psychology and Clinical Language Sciences,

University of Reading, RG6 6AL, UK

Telephone: +44 (0) 1183788579

Email: b.halldorsson@reading.ac.uk

Fax: +44(0) 1183786715

\section{Acknowledgements:}

The authors would like to thank the participating families in the Berkshire Child Anxiety Clinic at the University of Reading and Berkshire Healthcare NHS Foundation Trust, in particular Anna Alkozei, Sarah Cook, Amy Corcoran, Sue Cruddace, Rachel Gitau, Zoe Hughes, Jessica Karalus, Rebecca O'Grady, Ray Percy, Sarah Shildrick, Kerstin Thirlwall and Lucy Willetts for their help collecting and managing data.

\section{Role of funding source:}

Prof. Creswell was funded by a MRC Clinician Scientist award (G0601874). Participants were recruited and assessed within treatment trials funded by the MRC-NIHR partnership (09/800/17) and the MRC (G0802326). Prof. Creswell and Dr. Halldorsson are currently funded by an NIHR Research Professorship to Dr. Creswell (NIHR-RP-2014-04-018).

Conflict of Interest: None.

Access to research data: For access to research data, please contact corresponding author. 


\begin{abstract}
Objectives: It has been suggested that elevated maternal social anxiety may play a disorder specific role in maintaining childhood Social Anxiety Disorder (SAD), but few studies have examined whether mothers of children with SAD are more socially anxious than mothers of children with other anxiety disorders (ANX). This study set out to examine whether symptoms of social anxiety were more severe amongst mothers of 7-12 year old children presenting for treatment with SAD $(n=260)$ compared to those presenting with ANX $(n=138)$. In addition, we examined whether there were differences between these two groups in terms of maternal and paternal general anxiety, depression and stress.
\end{abstract}

Method: Parents of 7-12 year old children referred for treatment of SAD or ANX completed self-report questionnaire measures of emotional symptoms.

Results: Compared to mothers of children with ANX, mothers of children with SAD reported significantly higher levels of social anxiety, general anxiety, and depression. In addition, fathers of children with SAD reported significantly higher levels of anxiety, stress and depression than fathers of children with ANX.

Conclusions: This study is one of the few existing studies that have examined mothers' and fathers' psychopathology across different childhood anxiety disorders. Compared to parents of children with ANX, parents of children with SAD may have poorer mental health which may inhibit optimum child treatment outcomes for children with SAD. Thus, targeting parental psychopathology may be particularly important in the treatment of childhood SAD.

\title{
Practitioner points:
}

- Mothers of children with SAD are more socially anxious than mothers of children with ANX 
- Fathers of children with SAD are more anxious and depressed than fathers of children with ANX

- Consideration of parental psychopathology may be particularly important in the treatment of childhood SAD.

- Participants were predominantly of high socioeconomic status.

- Parental diagnostic information was not obtained.

\section{Keywords}

Social anxiety, parental psychopathology, treatment outcome, treatment for childhood anxiety 
Social Anxiety Disorder (SAD) is one of the most prevalent mental health disorders with a lifetime prevalence of approximately 13\% (Beesdo et al., 2007; Kessler et al., 2005). Half of all affected people have an onset before age 14 years of age (Kessler et al., 2005; Wittchen \& Fehm, 2003). Indeed, SAD has been found to be present in a significant proportion of preadolescent children referred for treatment for an anxiety disorder (e.g. Waite \& Creswell, 2014 (45\%); Kendall et al., 2010 (82\%)). Effective interventions for childhood SAD are clearly required given both the chronic course of SAD (Bittner et al., 2007) and its adverse long-term consequences, including depression, substance abuse, and impaired educational and occupational prospects (Beesdo et al., 2007; Schutters et al., 2011).

On the basis of the high comorbidity between childhood anxiety disorders, children with SAD are commonly treated with a transdiagnostic form of cognitive behavioural therapy (CBT) (e.g. Kendall \& Hedtke, 2006). However, recent findings suggest that the presence of $\mathrm{SAD}$ in the diagnostic spectrum is associated with poorer response to treatment compared to other anxiety disorders (e.g. remission rates of $40.6 \%$ vs. $72 \%$ (Ginsburg et al., 2011)). The reasons why children with SAD benefit less from traditional approaches than children with other anxiety disorders are not clear. It is possible that these treatments do not target maintenance mechanisms specific to SAD. For example, treatments which emphasise training children's social skills - based on the assumption that socially anxious children have social skills deficit (Beidel, Turner, \& Young, 2006; Spence, Donovan, \& Brechman-Toussaint, 2000) - appear to have better outcomes than CBT alone (Reynolds, Wilson, Austin, \& Hooper, 2012), but 30-50\% of children still retain their diagnosis post treatment (Beidel, Turner, \& Morris, 2000; Donovan, Cobham, Waters, \& Occhipinti, 2015; Öst, Cederlund, \& Reuterskiöld, 2015; Spence et al., 2000).

Another factor that may account for impaired treatment outcomes for children with SAD is elevated parental psychopathology. For example, it has been suggested that elevated 
parental anxiety is associated with poor treatment outcome for children with anxiety disorders (Murray, Creswell, \& Cooper, 2009; Rapee, 2001). However, this association has not always been found (e.g. Hudson et al., 2013; Kley, Heinrichs, Bender, \& TuschenCaffier, 2012; Rapee, 2000). Explanations for this inconsistency may be that treatment trials have typically included children from broad age ranges and with a range of anxiety disorders and parents with a range of anxiety symptoms, rather than considering specific anxiety subtypes (e.g. Compton et al., 2014; Schleider et al., 2015). These are notable limitations given that meta-analytic findings suggest that maternal psychopathology is more closely related to emotional problems in middle childhood (6-12 years) than adolescence (>13 years) (Connell \& Goodman, 2002). Furthermore, there is preliminary evidence for parental social anxiety disorder specificity in both the intergenerational transmission of anxiety (Cooper, Fearn, Willetts, Seabrook, \& Parkinson, 2006; Merikangas, Lieb, Wittchen, \& Avenevoli, 2003) and child treatment outcomes (Cooper, Gallop, Willetts, \& Creswell, 2008). In terms of disorder specificity, children with anxiety disorders are more likely than non-anxious children to have a parent with a lifetime anxiety disorder (Last, Hersen, Kazdin, Orvaschel, \& Perrin, 1991). Only two bottom up studies have explored the specificity of child-parent concordance of SAD and these both found a significant child-mother association for SAD (Cooper et al., 2006; Hughes, Furr, Sood, Barmish, \& Kendall, 2009). Notably, both studies included children and adolescents (6-16 years; Cooper et al., 2006; 7-14 years; Hughes et al., 2009) and did not report associations within more discrete age-groups. As such, it remains unclear whether the identified associations are consistent across the age range or at different developmental levels.

The current study builds on these two family history studies (i.e. Cooper et al., 2006; Hughes et al., 2009) to examine whether mothers of children with SAD report greater social anxiety symptoms than mothers of children with non-SAD forms of anxiety disorders (ANX) 
in order to establish whether this may be a useful candidate when considering the impaired treatment outcomes among children with SAD compared to children with ANX. In contrast to Cooper et al. (2006) and Hughes et al. (2009), who recruited children and adolescents, our sample consists of only pre-adolescent children ( 7 to 12 years) where maternal psychopathology has relatively strong effects on child emotional problems (Connell \& Goodman, 2002). We examined symptoms of social anxiety among mothers on the basis that adults with SAD experience frequent shifts in severity of symptoms around the diagnostic threshold (Merikangas, Avenevoli, Acharyya, Zhang, \& Angst, 2002; Wittchen, Lieb, Pfister, $\&$ Schuster, 2000). Indeed, up to $21.1 \%$ of adults with SAD at one point may not meet the diagnostic criteria for $\mathrm{SAD}$ at subsequent assessments, while continuing to experience elevated symptoms (Hovenkamp-Hermelink et al., 2016) and adults with sub-threshold social anxiety are comparable to adults with $\mathrm{SAD}$ in terms of associated impairment, quality of life, and comorbidity (Fehm, Beesdo, Jacobi, \& Fiedler, 2008). There is also evidence that the parenting behaviours that are hypothesised to play a role in the maintenance of childhood SAD are associated with elevated parental symptoms of social anxiety (see further Ollendick \& Benoit, 2012; Spence \& Rapee, 2016). For example, significant positive associations have been found between self-reported maternal social anxiety symptoms and overprotective parenting among non-clinical populations (Root, Hastings, \& Rubin, 2016).

Given the high comorbidity between social anxiety and depression (Beesdo et al., 2007; Cummings, Caporino, \& Kendall, 2014; Stein et al., 2001), we also explored associations between child anxiety disorders and maternal depressive symptoms. In an effort to address the neglect in recruiting fathers in research on childhood anxiety (Bögels \& Phares, 2008) we also examined whether fathers of children with SAD report greater symptoms of anxiety and depression than fathers of children with ANX. Finally, in order to examine whether elevated levels of parental psychopathology are specifically related to 
childhood SAD, we compared parental psychopathology among children with SAD and children with ANX. Given the high comorbidity of anxiety disorders in anxious children (Kendall et al., 2010), we controlled for this in sensitivity analyses, as well as other potential confounds (e.g. age, socio-economic status).

In summary, this study investigated the following hypotheses:

1. Compared to mothers of children with anxiety disorders other than SAD, mothers of children with SAD will self-report higher levels of social anxiety.

2. Compared to mothers of children with anxiety disorders other than SAD, mothers of children with SAD will self-report higher levels of depression.

3. In addition, we explored whether childhood SAD is associated with greater paternal anxiety and depression than other childhood anxiety disorders.

\section{Methods}

\section{Participants and procedure}

Three-hundred and ninety-eight children, aged 7-12 years, and their mothers $(n=375)$ and fathers $(n=272)$ participated in the study. Potential participants were invited for an initial assessment following a referral by a local health and education service personal to a specialist anxiety clinic and research centre in the UK. On the basis of assessments using the Anxiety Disorders Interview Schedule for DSM-IV for Children - Child and Parent Versions (ADISC/P; Silverman \& Albano, 1996), 260 (65.3\%) children met diagnostic criteria for SAD, and $138(34.7 \%)$ met criteria for ANX. Parents of all participants gave informed consent and children provided assent. All procedures received University and National Health Service ethical approval. Participating parents and children completed the ADIS-C/P and symptoms questionnaires, before initiating treatment either in University clinic rooms or in satellite clinics in their locality. 


\section{Measures}

\section{Diagnosis.}

Children were assigned a diagnosis on the basis of ADIS-C/P (Silverman \& Albano, 1996). Where children met symptom criteria for a diagnosis, based on either parent or child report, they were assigned a clinical severity rating (CSR) score ranging from 0 (complete absence of psychopathology) to 8 (severe psychopathology). Only those who met a symptom criteria with a CSR of 4 (moderate psychopathology) or more were considered to meet diagnostic criteria. Assessors (psychology undergraduates) were trained on the standard administration and scoring of the ADIS-C/P through verbal instruction, listening to assessment audio-recordings and participating in diagnostic consensus discussion. The first 20 interviews conducted were then discussed with a consensus team, led by an experienced diagnostician (Consultant Clinical Psychologist). The assessor and the consensus team independently allocated diagnoses and CSRs. Following the administration of 20 child and 20 parent interviews, inter-rater reliability for each assessor was checked, and if assessors achieved reliability of at least .85 they were then required to discuss just one in six interviews with the consensus team to prevent inter-rater drift. Overall reliability for the team was excellent. Reliability for the presence or absence of diagnosis was kappa=.98; and for the CSR intra-class correlation $=.99$.

\section{Symptom measures.}

The Spence Children's Anxiety Scale parent and child report (SCAS-p/c; Nauta et al., 2004; Spence, 1998) was administered to assess child and maternal reported symptoms of anxiety. Both versions have demonstrated concurrent validity and internal consistency (Nauta et al., 2004; Spence, 1998). Internal reliability based on data from the current sample was 
good (Chronbach's alpha $(\alpha)=.90$ for mother report; $\alpha=.88$ for father report, $\alpha=.91$ for child report).

Maternal social anxiety was assessed using the Social Interaction Anxiety Scale (SIAS; Mattick \& Clarke, 1998) and the Social Phobia Scale (SPS; Mattick \& Clarke, 1998). Both measures have demonstrated high internal reliability and concurrent validity (Mattick \& Clarke, 1998; Osman, Gutierrez, Barrios, Kopper, \& Chiros, 1998). Internal reliability, in this study, was good $(\alpha=.88$ for SIAS and $\alpha=.92$ for SPS).

Maternal general anxiety, stress and depression was assessed using the three relevant subscales from the Depression Anxiety and Stress Scale-21 (DASS-21; Lovibond \& Lovibond, 1995) which has demonstrated good internal consistency and concurrent validity (Antony, Bieling, Cox, Enns, \& Swinson, 1998). Internal reliability was good in this sample (DASS Depression, $\alpha=.91$; DASS Anxiety, $\alpha=.82$; DASS Stress, $\alpha=.88$, for mother report).

Due to the common challenge in obtaining data on paternal psychopathology (Bögels \& Phares, 2008; Phares, Fields, Kamboukos, \& Lopez, 2005) - with some notable exceptions (Bögels \& Siqueland, 2006; van der Bruggen, Bogels, \& Van Zeilst, 2010) - fathers were asked to complete a smaller number of measures and so paternal psychopathology was assessed only using the DASS-21 (Lovibond \& Lovibond, 1995). Internal reliability was good in this sample (DASS Depression, $\alpha=.87$; DASS Anxiety, $\alpha=.72$; DASS Stress, $\alpha=$ .83 , for father report).

\section{Results}

\section{Preliminary analyses}

Preliminary analyses were conducted to identify potential confounding variables. There was no significant association between child anxiety disorder group and child age 
$(t(396)=.053, p=.957))$, ethnicity $\left.\left(\chi^{2}(1)=.124, p=.725\right)\right)$, or gender $\left(\chi^{2}(1)=1,998, p=\right.$ .159). However, the groups did differ on socio-economic group status $\left(\chi^{2}(1)=8.144, p=\right.$ $.004)$, with relatively fewer children among the SAD group coming from families who were classified as higher/professionals than amongst those with ANX (National Statistics SocioEconomic Classification (NS-SEC; HMSO, 2005, see Table 1)), and child anxiety severity (SCAS-child/mother/father report; see Table 1). Further analyses, therefore, controlled for SES and SCAS scores (using the mother report when examining maternal symptoms and father report when examining paternal symptoms) in relation to the relevant dependent variables. SCAS total score mother/father report (without the social anxiety items) was entered as a potential confounding variable to account for the possibility that group differences may be a function of higher levels of anxiety symptoms (see further below). As SES, did not have a significant effect in any of the models, the results below are presented unadjusted for SES. We have highlighted where results changed when controlling for SCAS.

Table 2 shows the frequency of children's anxiety disorders, PTSD, and mood disorder (either Major Depressive Episode and/or Dysthymia), together with their scores on the questionnaires, and comorbid diagnoses. Compared to the ANX group, children with SAD were significantly more likely to have comorbid Separation Anxiety Disorder $\left(\chi^{2}(1)=\right.$ 10.379, $p<.001)$, Generalized Anxiety Disorder $\left(\chi^{2}(1)=33.058, \mathrm{p}<.001\right)$, and Mood Disorders $\left(\chi^{2}(1)=14.146, p<.001\right)$. Significantly more children in the ANX group met diagnostic criteria for Panic Disorder without Agoraphobia $\left(\chi^{2}(1)=5.652, p=.017\right)$ and Anxiety Disorder Not Otherwise Specified $\left(\chi^{2}(1)=8.654, p=.003\right)$. For the examination of specificity in $\mathrm{SAD}$, five sensitivity analyses were conducted excluding children from both groups with comorbid (i) Separation Anxiety Disorder (ii) GAD or (iii) Mood Disorders, (iv) Panic Disorder, and (v) Anxiety Disorder Not Otherwise Specified. This approach was taken, rather than entering diagnostic or self-report scores as covariates due to concerns about 
collinearity. A further set of sensitivity analyses were conducted in which the SAD group comprised only those children who had SAD as the primary disorder.

Analyses were also conducted to examine group differences on total and social anxiety symptoms (see Table 2). As expected, children with SAD scored significantly higher than the ANX children on the SCAS-mother/father/child social anxiety subscales, (SCASmother social anxiety; $t(361)=-9.266, p<.001, r=.46$; SCAS-father social anxiety; $t(267)=$ -7.977, $p<.001, r=.45$; SCAS-child social anxiety; $t(379)=-5.964, p<.001, r=.31)$.

Children with SAD also scored significantly higher on both parent and child reported total anxiety (SCAS-mother, $t(363)=-5.112, p<.001, r=.27$; SCAS-father, $t(270)=-5.414, p<$ $.001, r=.32$; SCAS-child $, t(379)=-3.441, p<.001, r=.18)$. When scores for social anxiety were subtracted from total anxiety scores, children with SAD continued to score significantly higher than children with ANX, for both parent (SCAS-mother, $t(361)=-3.344, p<.001, r=$ $.20 ;$ SCAS-father, $t(272)=-3.491, p=.001, r=.21)$ and child report $(t(379)=-2.618, p=$ $.009, r=.14)$.

\section{Hypothesis testing}

Separate multivariate analyses of variance (MANOVAs) were conducted (using Pillai's trace) for (i) the social anxiety measures (SIAS and SPS), and (ii) the DASS subscales in order to make full use of the available data (as there was missing data for $n=17$ mothers on the DASS). For mothers' self-reported social anxiety (SIAS and SPS), there was a significant group difference between mothers of children with SAD and mothers of children with $\operatorname{ANX}\left(F(2,352)=3.673, p=.026\right.$ partial $\left.\eta^{2}=.02\right)$. As shown in Table 3, tests of between subjects effects revealed that mothers of children with SAD scored significantly higher than mothers of ANX children on the SIAS $\left(F(1,353)=7.165, p=.008\right.$, partial $\eta^{2}=$ $.02)$ and this approached significance on the SPS $\left(F(1,353)=3.202, p=.07\right.$, partial $\eta^{2}=$ 
.01). For maternal self-reported DASS-Depression, Anxiety and Stress, there was a significant group difference $\left(F(3,334)=3.456, p=.017\right.$ partial $\left.\eta^{2}=.03\right)$ which reflected significantly higher scores for mothers of children with SAD than mothers of ANX children on DASS-Depression $\left(F(1,336)=7.884, p=.005\right.$, partial $\left.\eta^{2}=.02\right)$, and DASS-Anxiety $(F$ $(1,336)=6.752, p=.01$, partial $\left.\eta^{2}=.02\right)$, but not on DASS-Stress $(F(1,336)=2.024, p=$ .156 , partial $\left.\eta^{2}=.01\right)$. For fathers' self-reported psychopathology, using Pillai's trace, there was a significant group difference between fathers of children with SAD and fathers of children with $\operatorname{ANX}(F(3,258)=2.735, p=.044)$, reflecting significantly higher scores for fathers of children with SAD compared to fathers of ANX children on all DASS subscales (i.e. DASS-Depression $\left(F(1,260)=5.242, p=.023\right.$, partial $\left.\eta^{2}=.02\right)$, DASS-Anxiety $(F(1$, $260)=4.510, p=.035$, partial $\left.\eta^{2}=.02\right)$ and DASS-Stress $(F(1,260)=7.337, p=.007$, partial $\left.\eta^{2}=.027\right)$. As children with SAD scored significantly higher for both parent and child reported total anxiety when social anxiety scores were subtracted from the total score (SCASno social), analyses were run controlling for the SCAS total score mother/father report without the social anxiety items. This did not alter the results, except for paternal reported anxiety that became non-significant: DASS-A-f $\left(F(1,256)=2.198, p=.139\right.$, partial $\eta^{2}=$ $.01)$.

Sensitivity analyses were conducted by comparing the SAD and ANX group on questionnaires scores after excluding children with (i) Separation Anxiety Disorder ( $\mathrm{n}=231$ ), (ii) GAD ( $\mathrm{n}=257$ ), (iii) Mood Disorder ( $\mathrm{n}=56$ ), (iv) Panic Disorder without Agoraphobia $(\mathrm{n}=10)$, and (v) Anxiety Disorder Not Otherwise Specified $(\mathrm{n}=14)$ (see Table 4). Differences in SIAS scores remained significant when children with GAD, Mood Disorders, Panic Disorder and Anxiety Disorder Not Otherwise Specified were excluded, but this was not the case when children with Separation Anxiety Disorder were excluded (and the effect size reduced from .019 to .009). Differences in SPS scores were no longer significant across all 
these follow-up analyses, but effect sizes remained the same (partial $\eta^{2}=.01$ ), except for when children with Separation Anxiety Disorder were excluded. Group differences in maternal depression were robust across all of these sensitivity analyses. This was also the case for maternal anxiety (except for when children with Separation Anxiety Disorder or GAD were excluded). Notably, differences in paternal depression, anxiety, and stress remained significant when children with Separation Anxiety Disorder, Mood Disorders, Panic Disorder, Anxiety Disorder Not Otherwise Specified were excluded; although this was not the case when children with GAD were excluded (but the effect size remained similar).

The analyses were repeated including only those children who had SAD as a primary diagnosis $(n=87)$ versus those children who did not have SAD in their diagnostic profile $(n=138)$. Mothers of children with SAD scored significantly higher than mothers of ANX children on all measures (partial $\eta^{2}$ 's ranging from .029-.048) except for DASS-Stress ( $F$ $(1,183)=.652, p=.420$, partial $\left.\eta^{2}=.004\right)$. For paternal report, no significant group differences emerged $\left(F(3,147)=1.744, p=.161\right.$, partial $\left.\eta^{2}=.034\right)$.

\section{Discussion}

As hypothesised, compared to the mothers of children with ANX, mothers of children with SAD have more severe symptoms of social anxiety and depression. In addition, fathers of socially anxious children reported higher anxiety, stress and depressive symptoms than fathers of children with other anxiety disorders. These findings were robust when children with common comorbid disorders were excluded from the analyses, as well as when the SAD group was restricted to those for whom SAD was the primary disorder (with a few exceptions which we discuss further below). It was notable that the children with SAD had more severe anxiety overall than ANX children, even after taking into account their social anxiety 
symptoms. However, for the most part, findings were consistent when child anxiety severity was controlled in the analysis.

The finding that, compared to mothers of children with ANX, mothers of children with SAD had significantly higher levels of both social anxiety and depression is in line with the one previous study that examined current parental anxiety diagnoses: Cooper and colleagues (2006), in a study of familial aggregation of anxiety disorders, found that children with a diagnosis of SAD were more likely to have mothers with a diagnosis of $\mathrm{SAD}$ and depression than did anxious children with non-SAD diagnoses. Recent evidence suggests that children with SAD are less likely to respond to generic CBT interventions than children who have other anxiety problems than SAD (Ginsburg et al., 2011). It is possible that the elevated social anxiety among the mothers of children with SAD serves to promote a style of anxious parenting behaviours that militates against good treatment outcomes (Budinger, Drazdowski, \& Ginsburg, 2013). For example, socially anxious parents may transfer negative information to their child regarding social stimuli or social evaluation (Ollendick \& Benoit, 2012; Ollendick \& Hirshfeld-Becker, 2002). Parents may also model anxious/avoidance which could develop and maintain a child's fear of social situations (De Rosnay, Cooper, Tsigaras, \& Murray, 2006) and prevent them from 'testing out' their inaccurate social beliefs (Clark \& Wells, 1995).

We found elevated depressive symptoms among both mothers and fathers of children with SAD compared to children with other anxiety disorders. This could also be a factor in impaired child treatment outcomes, as depressed parents may be less able to ensure child treatment compliance (Southam-Gerow, Kendall, \& Weersing, 2001). For example, impaired motivation among depressed parents may make it difficult for them to encourage their child to face anxiety and experience novel social situations. Finally, although we only used a general measure of fathers' depression, anxiety, and stress to minimise the demand on fathers 
who are often difficult to recruit into research (e.g. Bögels \& Phares, 2008; Phares et al., 2005), it is interesting that fathers of children with SAD reported elevated levels of stress, anxiety and depression. It has been suggested that fathers play an important and different role to mothers in the socialization of children and in the protection against child anxiety (for review see Bögels \& Phares, 2008). For example, a recent study found that 9-11 year old children with high social anxiety were more influenced by fathers' compared to mothers' reaction to social stimuli (Bögels, Stevens, \& Majdandžić, 2011).

Strengths of this study include a large clinical population which allowed for the specific consideration of childhood $\mathrm{SAD}$, diagnosed on the basis of systematic and reliable assessments. In addition, although it was not our primary focus, this study is one of the few existing studies that have examined fathers' psychopathology within the context of childhood anxiety disorders. Limitations are that the participants were predominantly of a high socioeconomic status, limiting the generalizability of the findings. It is notable that we found that fewer children with SAD were of high socio-economic status than children with ANX. While controlling for this in the analysis did not significantly alter the results, it is possible that SES and factors associated with SES may have had broader effects than we were able to control for. For example, among adults, SAD is frequently associated with poor financial situation, low social class and unemployment (Wittchen \& Fehm, 2001, 2003). Our findings reflect the possibility that socially anxious parents of children with SAD may have lower SES, as measured by employment status, as a result of their social anxiety. Alternatively, they may reflect a risk of social anxiety in children as a response to factors associated with relatively low SES. As few studies have compared socio-economic status across different childhood anxiety disorders any conclusions must remain tentative, particularly in the light of recent Australian data that did not find significant differences in social and environmental factors, such as family income, between different anxiety disorders (Spence, Zubrick, \& Lawrence, 
2017). Critically, responses from parents were solely based on self-report measures and formal diagnoses were not made. Consequently, the study is unable to draw conclusions about specific parental anxiety disorders. Finally, the cross-sectional nature of the study means that the direction of effects cannot be established - that is, it is possible that parental psychopathology is a response to offspring anxiety. Further prospective longitudinal and experimental research is necessary to clarify this. While acknowledging these limitations, this study provides evidence to suggest that parental psychopathology should be considered as a potential factor in studies seeking to explain impaired treatment outcomes among children with SAD. 


\section{References}

Antony, M. M., Bieling, P. J., Cox, B. J., Enns, M. W., \& Swinson, R. P. (1998). Psychometric properties of the 42-item and 21-item versions of the Depression Anxiety Stress Scales in clinical groups and a community sample. Psychological Assessment, 10(2), 176-181. doi:10.1037//1040-3590.10.2.176

Beesdo, K., Bittner, A., Pine, D. S., Stein, M. B., Hofler, M., Lieb, R., \& Wittchen, H. U. (2007). Social anxiety disorder: patterns of incidence and secondary depression risk. European Neuropsychopharmacology, 17, S511-S512. doi:10.1016/s0924$977 \times(07) 70788-5$

Beidel, D. C., Turner, S. M., \& Morris, T. L. (2000). Behavioral treatment of childhood social phobia. Journal of Consulting and Clinical Psychology, 68(6), 1072.

Beidel, D. C., Turner, S. M., \& Young, B. J. (2006). Social effectiveness therapy for children: Five years later. Behavior Therapy, 37(4), 416-425.

Bittner, A., Egger, H. L., Erkanli, A., Costello, J. E., Foley, D. L., \& Angold, A. (2007). What do childhood anxiety disorders predict? Journal of Child Psychology and Psychiatry, 48(12), 1174-1183. doi:10.1111/j.1469-7610.2007.01812.x

Bögels, S., \& Phares, V. (2008). Fathers' role in the etiology, prevention and treatment of child anxiety: A review and new model. Clinical Psychology Review, 28(4), 539-558. doi:10.1016/j.cpr.2007.07.011

Bögels, S., \& Siqueland, L. (2006). Family Cognitive Behavioral Therapy for Children and Adolescents With Clinical Anxiety Disorders. Journal of the American Academy of Child \& Adolescent Psychiatry, 45(2), 134-141. doi:http://dx.doi.org/10.1097/01.chi.0000190467.01072.ee

Bögels, S., Stevens, J., \& Majdandžić, M. (2011). Parenting and social anxiety: Fathers' versus mothers' influence on their children's anxiety in ambiguous social situations. Journal of Child Psychology and Psychiatry, 52(5), 599-606.

Budinger, M. C., Drazdowski, T. K., \& Ginsburg, G. S. (2013). Anxiety-promoting parenting behaviors: a comparison of anxious parents with and without social anxiety disorder. Child Psychiatry \& Human Development, 44(3), 412-418.

Clark, D. M., \& Wells, A. (1995). A cognitive model of social phobia. In R. G. Heimberg, M. Liebowitz, D. Hope, \& F. Schneier (Eds.), Social phobia: Diagnosis, assessment and treatment (pp. 69-93). New York: Guilford Press.

Compton, S. N., Peris, T. S., Almirall, D., Birmaher, B., Sherrill, J., Kendall, P. C., . . Rynn, M. A. (2014). Predictors and moderators of treatment response in childhood anxiety disorders: Results from the CAMS trial. Journal of Consulting and Clinical Psychology, 82(2), 212.

Connell, A. M., \& Goodman, S. H. (2002). The association between psychopathology in fathers versus mothers and children's internalizing and externalizing behavior problems: A meta-analysis. Psychological Bulletin, 128(5), 746-773. doi:10.1037/0033-2909.128.5.746

Cooper, P. J., Fearn, V., Willetts, L., Seabrook, H., \& Parkinson, M. (2006). Affective disorder in the parents of a clinic sample of children with anxiety disorders. Journal of Affective Disorder, 93, 205-212.

Cooper, P. J., Gallop, C., Willetts, L., \& Creswell, C. (2008). Treatment response in child anxiety is differentially related to the form of maternal anxiety disorder. Behavioural and Cognitive Psychotherapy, 36(01), 41-48. 
Cummings, C. M., Caporino, N. E., \& Kendall, P. C. (2014). Comorbidity of anxiety and depression in children and adolescents: 20 years after. Psychological Bulletin, 140(3), 816.

De Rosnay, M., Cooper, P. J., Tsigaras, N., \& Murray, L. (2006). Transmission of social anxiety from mother to infant: an experimental study using a social referencing paradigm. Behaviour Research and Therapy, 44, 1165-1175.

Donovan, C. L., Cobham, V., Waters, A. M., \& Occhipinti, S. (2015). Intensive Group-Based CBT for Child Social Phobia: A Pilot Study. Behavior Therapy, 46(3), 350-364. doi:http://dx.doi.org/10.1016/j.beth.2014.12.005

Fehm, L., Beesdo, K., Jacobi, F., \& Fiedler, A. (2008). Social anxiety disorder above and below the diagnostic threshold: prevalence, comorbidity and impairment in the general population. Social Psychiatry and Psychiatric Epidemiology, 43(4), 257-265.

Ginsburg, G. S., Sakolsky, D., Piacentini, J., Walkup, J. T., Coffey, K. A., Keeton, C. P., . . McCracken, J. T. (2011). Remission after acute treatment in children and adolescents with anxiety disorders: Findings from the CAMS. Journal of Consulting and Clinical Psychology, 79(6), 806-813. doi:10.1037/a0025933

HMSO. (2005). The National Statistics Socio-Economic Classification User Manual. Basingstoke: Palgrave MacMillan.

Hovenkamp-Hermelink, J. H. M., Riese, H., van der Veen, D. C., Batelaan, N. M., Penninx, B. W. J. H., \& Schoevers, R. A. (2016). Low stability of diagnostic classifications of anxiety disorders over time: A six-year follow-up of the NESDA study. Journal of Affective Disorders, 190, 310-315. doi:http://dx.doi.org/10.1016/i.jad.2015.10.035

Hudson, J. L., Lester, K. J., Lewis, C. M., Tropeano, M., Creswell, C., Collier, D. A., . . Eley, T. C. (2013). Predicting outcomes following cognitive behaviour therapy in child anxiety disorders: the influence of genetic, demographic and clinical information. Journal of Child Psychology and Psychiatry, 54(10), 1086-1094. doi:10.1111/jcpp.12092

Hughes, A. A., Furr, J. M., Sood, E. D., Barmish, A. J., \& Kendall, P. C. (2009). Anxiety, mood, and substance use disorders in parents of children with anxiety disorders. Child Psychiatry and human development, 40(3), 405-419.

Kendall, P. C., Compton, S. N., Walkup, J. T., Birmaher, B., Albano, A. M., Sherrill, J., ... Piacentini, J. (2010). Clinical characteristics of anxiety disordered youth. Journal of Anxiety Disorders, 24(3), 360-365. doi:http://dx.doi.org/10.1016/i.janxdis.2010.01.009

Kendall, P. C., \& Hedtke, K. A. (2006). Coping Cat workbook. 2nd. Ardmore, PA: Workbook.

Kessler, R. C., Berglund, P., Demler, O., Jin, R., Merikangas, K. R., \& Walters, E. E. (2005). Lifetime prevalence and age-of-onset distributions of DSM-IV disorders in the national comorbidity survey replication. Archives of General Psychiatry, 62(6), 593602. doi:10.1001/archpsyc.62.6.593

Kley, H., Heinrichs, N., Bender, C., \& Tuschen-Caffier, B. (2012). Predictors of outcome in a cognitive-behavioral group program for children and adolescents with social anxiety disorder. Journal of anxiety disorders, 26(1), 79-87. doi:http://dx.doi.org/10.1016/i.janxdis.2011.09.002

Last, C. G., Hersen, M., Kazdin, A. E., Orvaschel, H., \& Perrin, S. (1991). Anxiety disorders in children and their families. Archives of General Psychiatry, 48, 928-934.

Lovibond, S. H., \& Lovibond, P. F. (1995). Manual for the Depression Anxiety Stress Scales (2nd ed.). Sydney: Psychology Foundation. 
Mattick, R. P., \& Clarke, A. C. (1998). Development and validation of measures of social phobia scrutiny fear and social interaction anxiety. Behaviour, Research and Therapy, 36, 455-470.

Merikangas, K. R., Avenevoli, S., Acharyya, S., Zhang, H., \& Angst, J. (2002). The spectrum of social phobia in the Zurich cohort study of young adults. Biological Psychiatry, 51(1), 81-91.

Merikangas, K. R., Lieb, R., Wittchen, H. U., \& Avenevoli, S. (2003). Family and high-risk studies of social anxiety disorder. Acta Psychiatrica Scandinavica, 108(s417), 28-37.

Murray, L., Creswell, C., \& Cooper, P. J. (2009). The development of anxiety disorders in childhood: an integrative review. Psychological Medicine, 39(09), 1413-1423.

Nauta, M. H., Scholing, A., Rapee, R. M., Abbott, M., Spence, S. H., \& Waters, A. (2004). A parent-report measure of children's anxiety: Psychometric properties and comparison with child-report in a clinic and normal sample. Behaviour Research and Therapy, 42, 813-839. doi:10.1016/S0005-7967(03)00200-6

Ollendick, T. H., \& Benoit, K. E. (2012). A Parent-Child Interactional Model of Social Anxiety Disorder in Youth. Clinical Child and Family Psychology Review, 15(1), 81-91. doi:10.1007/s10567-011-0108-1

Ollendick, T. H., \& Hirshfeld-Becker, D. R. (2002). The developmental psychopathology of social anxiety disorder. Biological Psychiatry, 51(1), 44-58. doi:http://dx.doi.org/10.1016/S0006-3223(01)01305-1

Osman, A., Gutierrez, P. M., Barrios, F. X., Kopper, B. A., \& Chiros, C. E. (1998). The Social Phobia and Social Interaction Anxiety Scales: Evaluation of Psychometric Properties. Journal of Psychopathology and Behavioral Assessment, 20(3), 249-264. doi:10.1023/a:1023067302227

Öst, L.-G., Cederlund, R., \& Reuterskiöld, L. (2015). Behavioral treatment of social phobia in youth: Does parent education training improve the outcome? Behaviour Research and Therapy, 67(0), 19-29. doi:http://dx.doi.org/10.1016/j.brat.2015.02.001

Phares, V., Fields, S., Kamboukos, D., \& Lopez, E. (2005). Still looking for Poppa.

Rapee, R. M. (2000). Group treatment of children with anxiety disorders: Outcome and predictors of treatment response. Australian Journal of Psychology, 52(3), 125-129.

Rapee, R. M. (2001). The development of generalized anxiety. In M. W. Vasey \& M. R. Dadds (Eds.), The Developmental Psychopathlogy of Anxiety (pp. 481-503). Oxford: Oxford University Press.

Reynolds, S., Wilson, C., Austin, J., \& Hooper, L. (2012). Effects of psychotherapy for anxiety in children and adolescents: A meta-analytic review. Clinical Psychology Review, 32(4), 251-262.

Root, A. E., Hastings, P. D., \& Rubin, K. H. (2016). The Parenting Behaviors of Shy-Anxious Mothers: The Moderating Role of Vagal Tone. Journal of Child and Family Studies, 25(4), 1325-1333.

Schleider, J. L., Ginsburg, G. S., Keeton, C. P., Weisz, J. R., Birmaher, B., Kendall, P. C., . . Walkup, J. T. (2015). Parental psychopathology and treatment outcome for anxious youth: Roles of family functioning and caregiver strain. Journal of Consulting and Clinical Psychology, 83(1), 213.

Schutters, S. I. J., Dominguez, M. d. G., Knappe, S., Lieb, R., van Os, J., Schruers, K. R. J., \& Wittchen, H. U. (2011). The association between social phobia, social anxiety cognitions and paranoid symptoms. Acta Psychiatrica Scandinavica, 125, 213-227. 
Silverman, W. K., \& Albano, A. M. (1996). The anxiety disorders interview schedule for DSMIV - child and parent versions. San Antonio. TX: Psychological Corporation.

Southam-Gerow, M. A., Kendall, P. C., \& Weersing, V. R. (2001). Examining outcome variability: Correlates of treatment response in a child and adolescent anxiety clinic. Journal of Clinical Child Psychology, 30(3), 422-436.

Spence, S. H. (1998). A measure of anxiety symptoms among children. Behaviour Research and Therapy, 36(5), 545 - 566. doi:10.1016/S0005-7967(98)00034-5

Spence, S. H., Donovan, C. L., \& Brechman-Toussaint, M. (2000). The treatment of childhood social phobia: The effectiveness of a social skills training-based, cognitivebehavioural intervention, with and without parental involvement. Journal of Child Psychology and Psychiatry, 41(6), 713-726.

Spence, S. H., \& Rapee, R. M. (2016). The etiology of social anxiety disorder: An evidencebased model. Behavior Research and Therapy, 86, 50-67. doi:10.1016/j.brat.2016.06.007

Spence, S. H., Zubrick, S. R., \& Lawrence, D. (2017). A profile of social, separation and generalized anxiety disorders in an Australian nationally representative sample of children and adolescents: Prevalence, comorbidity and correlates. Australian \& New Zealand Journal of Psychiatry, 0004867417741981.

Stein, M. B., Fuetsch, M., Müller, N., Höfler, M., Lieb, R., \& Wittchen, H.-U. (2001). Social anxiety disorder and the risk of depression: a prospective community study of adolescents and young adults. Archives of General Psychiatry, 58(3), 251-256.

van der Bruggen, C. O., Bogels, S. M., \& Van Zeilst, N. (2010). What influences parental controlling behaviour? The role of parent and child trait anxiety. Cognition and Emotion, 24(1), 141-149.

Waite, P., \& Creswell, C. (2014). Children and adolescents referred for treatment of anxiety disorders: Differences in clinical characteristics. Journal of Affective Disorders, 167(0), 326-332. doi:http://dx.doi.org/10.1016/j.jad.2014.06.028

Wittchen, H. U., \& Fehm, L. (2001). Epidemiology, patterns of comorbidity, and associated disabilities of social phobia. Psychiatric Clinics of North America, 24(4), 617-641.

Wittchen, H. U., \& Fehm, L. (2003). Epidemiology and natural course of social fears and social phobia. Acta Psychiatrica Scandinavica Supplementum, 108(417), 4-18.

Wittchen, H. U., Lieb, R., Pfister, H., \& Schuster, P. (2000). The waxing and waning of mental disorders: evaluating the stability of syndromes of mental disorders in the population. Comprehensive Psychiatry, 41(2), 122-132. 
RUNNING HEAD: PARENTAL PSYCHOPATHOLOGY AND CHILDHOOD SOCIAL ANXIETY

\section{Table 1.}

Demographics by group

$$
\operatorname{SAD}(\mathrm{n}=260) \quad \text { ANX }(\mathrm{n}=138) \quad \text { Statistics }
$$

\begin{tabular}{lccc}
\hline Child age, M (SD) ${ }^{\mathrm{a}}$ & $9.72(1.60)$ & $9.73(1.48)$ & $t(396)=.053, p=.957$ \\
Child ethnicity (\% White) & 85,4 & 84.1 & $\chi^{2}(1)=.124, p=.725$ \\
Child gender (\% boys) & 46.9 & 54.3 & $\chi^{2}(1)=1,998, p=.159$ \\
SES (\% higher/professional) & & & \\
\end{tabular}

Note: $\mathrm{SAD}=$ Social Anxiety Disorder; ANX = Other Anxious; $\mathrm{M}=$ mean; $\mathrm{SD}=$ standard deviation; $\mathrm{SES}=$ Socio-economic status (SES) based on National Statistics Socio-Economic Classification (HMSO, 2005) where classes 1-3 were categorised as high SES.

a Age of child at initial assessment 
Table 2.

Frequency of comorbid diagnosis and questionnaire scores

\begin{tabular}{|c|c|c|c|}
\hline & $\begin{array}{c}\text { SAD } \\
(n=260)\end{array}$ & $\begin{array}{c}\text { ANX } \\
(n=138)\end{array}$ & Statistics \\
\hline Separation Anxiety Disorder \% (n) & $63.8(166)$ & $47.1(65)$ & $\chi^{2}(1)=10.379, p<.001$ \\
\hline Generalized Anxiety Disorder \% (n) & $74.6(194)$ & $45.7(63)$ & $\chi^{2}(1)=33.058, p<.001$ \\
\hline Mood Disorder \% (n) & $18.8(49)$ & $5.1(7)$ & $\chi^{2}(1)=14.146, p<.001$ \\
\hline Panic Dis. w/o Agoraphobia \% (n) & $1.2(3)$ & $5.1(7)$ & $\chi^{2}(1)=5.652, p=.017$ \\
\hline Panic Dis. with Agoraphobia \% (n) & $0.8(2)$ & $0.7(1)$ & $\chi^{2}(1)=.002, p=.961$ \\
\hline Agoraphobia w/o Panic Disorder \% (n) & $4.6(12)$ & $8.7(12)$ & $\chi^{2}(1)=2.649, p=.104$ \\
\hline Specific Phobia \% (n) & $44.2(115)$ & $44.9(62)$ & $\chi^{2}(1)=.018, p=.894$ \\
\hline Obsessive Compulsive Disorder \% (n) & $4.2(11)$ & $2.2(3)$ & $\chi^{2}(1)=1.124, p=.289$ \\
\hline Anxiety Disorder NOS \% (n) & $1.5(4)$ & $7.2(10)$ & $\chi^{2}(1)=8.654, p=.003$ \\
\hline Post-Traumatic Stress Disorder \% (n) & $0.4(1)$ & $0.0(0)$ & $\chi^{2}(1)=.532, p=.466$ \\
\hline SCAS-m total score, $\mathrm{M}$ (SD) & $43.27(16.66)$ & $34.30(14.22)$ & $t(363)=-5.112, p<.001, r=.27$ \\
\hline SCAS-f total score, M (SD) & $34.04(13.19)$ & $25.57(11.24)$ & $t(270)=-5.414, p<.001, r=.32$ \\
\hline SCAS-c total score, $\mathrm{M}$ (SD) & $41.84(19.26)$ & $35.04(16.51)$ & $t(379)=-3.441, p<.001, r=.18$ \\
\hline SCAS-social-m, M (SD) & $9.95(3.97)$ & $5.98(3.65)$ & $t(361)=-9.266, p<.001, r=.46$ \\
\hline SCAS-social-f, M (SD) & $8.50(3.79)$ & $5.08(2.66)$ & $t(267)=-7.977, p<.001, r=.45$ \\
\hline SCAS-social-c, M (SD) & $7.31(4.01)$ & $4.91(3.17)$ & $t(379)=-5.964, p<.001, r=.31$ \\
\hline SCAS-no social-m, M (SD) & $33.36(14.45)$ & $28.24(12.52)$ & $t(361)=-3.344, p<.001, r=.20$ \\
\hline SCAS-no social-f, M (SD) & $24.97(11.05)$ & $20.32(9.94)$ & $t(272)=-3.491, p=.001, r=.21$ \\
\hline SCAS-no social-c, M (SD) & $34.53(16.30)$ & $30.13(14.19)$ & $t(379)=-2.618, p=.009, r=.14$ \\
\hline
\end{tabular}


Note: Anxiety Disorder NOS = Anxiety Disorder Not Otherwise Specified; Mood disorder = either Major Depressive Episode and/or Dysthymia; SCAS-m = Spence Children's Anxiety Scale-mother report; SCAS-f= Spence Children's Anxiety Scale-father report; SCAS-c = Spence Children's Anxiety Scale-child report; SCAS-social-m = Spence Children's Anxiety Scale-social phobia subscale-mother report; SCAS-social-f = Spence Children's Anxiety Scale social phobia subscale-father report; SCAS-social-c = Spence Children's Anxiety Scale social phobia subscale-child report; SCAS-no social-m = Spence Children's Anxiety Scale excluding social phobia subscale-mother report; SCAS-no social-f = Spence Children's Anxiety Scale excluding social phobia subscale -father report; SCAS-no social-c = Spence Children's Anxiety Scale excluding social phobia subscale-child report; $\mathrm{M}=$ mean; $\mathrm{SD}=$ standard deviation. 
RUNNING HEAD: PARENTAL PSYCHOPATHOLOGY AND CHILDHOOD SOCIAL ANXIETY

Table 3.

Parental psychopathology

\begin{tabular}{lccc}
\hline Questionnaire & SAD & ANX & Statistics \\
\hline SIAS, M (SD) & $20.47(13.25)$ & $16.69(11.27)$ & $F(1,353)=7.165, p=.008$, partial $\eta^{2}=.02$ \\
SPS, M (SD) & $10.57(10.54)$ & $8.51(9.57)$ & $F(1,353)=3.202, p=.07$, partial $\eta^{2}=.01$ \\
DASS-D-m, M (SD) & $9.04(8.49)$ & $6.38(7.55)$ & $F(1,336)=7.884, p=.005$, partial $\eta^{2}=.02$ \\
DASS-A-m, M (SD) & $6.45(7.23)$ & $4.41(5.81)$ & $F(1,336)=6.752, p=.010$, partial $\eta^{2}=.02$ \\
DASS-S-m, M (SD) & $13.17(9.15)$ & $11.68(8.88)$ & $F(1,336)=2.024, p=.156$, partial $\eta^{2}=.01$ \\
DASS-D-f, M (SD) & $7.74(6.94)$ & $5.74(6.75)$ & $F(1,260)=5.242, p=.023$, partial $\eta^{2}=.02$ \\
DASS-A-f, M (SD) & $4.16(4.84)$ & $2.91(4.29)$ & $F(1,260)=4.510, p=.035$, partial $\eta^{2}=.02$ \\
DASS-S-f, M (SD) & $13.21(7.43)$ & $10.57(7.99)$ & $F(1,260)=7.337, p=.007$, partial $\eta^{2}=.03$ \\
\hline
\end{tabular}

Note : SIAS = Social Interaction Anxiety Scale; SPS = Social Phobia Scale; DASS-D-m = DASS-Depression subscalemother report; DASS-A-m = DASS-Anxiety subscale-mother report; DASS-S-m = DASS-Stress subscale-mother report; DASS-d-f = DASS-Depression subscale-father report; DASS-A-f = DASS-Anxiety subscale-father report; DASS-S-f = DASS-Stress subscale-father report; $\mathrm{M}=$ mean; $\mathrm{SD}=$ standard deviation 
RUNNING HEAD: PARENTAL PSYCHOPATHOLOGY AND CHILDHOOD SOCIAL ANXIETY

Table 4.

Sensitivity analysis

Excluded Disorder

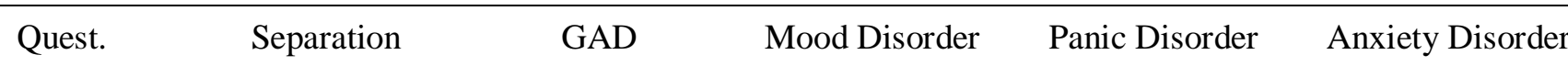

Anxiety

w/o Agoraphobia

NOS

SIAS $\quad F(1,149)=1.294, \quad F(1,124)=6.178, \quad F(1,303)=6.028, \quad F(1,345)=6.679, \quad F(1,340)=6.534$, $p=.257, \eta^{2}=.01 \quad p=.014, \eta^{2}=.05 \quad p=.015, \eta^{2}=.02 \quad p=.010 \eta^{2}=.02 \quad p=.011, \eta^{2}=.02$

SPS $\quad F(1,149)=.463, \quad F(1,124)=1.378, \quad F(1,303)=2.395, \quad F(1,345)=3.277, \quad F(1,340)=2.434$, $p=.497, \eta^{2}=.003 \quad p=.243, \eta^{2}=.01 \quad p=.123, \eta^{2}=.01 \quad p=.071, \eta^{2}=.01 \quad p=.120, \eta^{2}=.01$

DASS-D- $\quad F(1,139)=6.557, \quad F(1,118)=6.021, \quad F(1,287)=4.738, \quad F(1,328)=8.041, \quad F(1,323)=6.766$,

m. $p=.012, \eta^{2}=.05 \quad p=.016, \eta^{2}=.05 \quad p=.030, \eta^{2}=.02 \quad p=.005, \eta^{2}=.02 \quad p=.010, \eta^{2}=.02$

DASS-A $-\quad F(1,139)=2.669, \quad F(1,118)=1.179, \quad F(1,287)=4.950, \quad F(1,328)=6.591, \quad F(1,323)=6.324$

m. $p=.105, \eta^{2}=.02 \quad p=.280, \eta^{2}=.01 \quad p=.027, \eta^{2}=.02 \quad p=.011, \eta^{2}=.02 \quad p=.012, \eta^{2}=.02$

DASS-S- $\quad F(1,139)=.642, \quad F(1,118)=.626, \quad F(1,287)=1.720, \quad F(1,328)=1.809, \quad F(1,323)=1.520$,

m.

$p=.424, \eta^{2}=.01 \quad p=.431, \eta^{2}=.01$

$p=.191, \eta^{2}=.01$

$p=.180, \eta^{2}=.01$

$p=.217, \eta^{2}=.01$

DASS-D- $\quad F(1,116)=10.75, \quad F(1,93)=1.480, \quad F(1,231)=6.816, \quad F(1,252)=5.327, \quad \mathrm{~F}(1,252)=5.327$,

f.

$p=.001, \eta^{2}=.09 \quad p=.227, \eta^{2}=.02$

$p=.010, \eta^{2}=.03$

$p=.022, \eta^{2}=.02$

$p=.022, \eta^{2}=.02$

DASS-A- $\quad \mathrm{F}(1,116)=4.488, \quad F(1,93)=.313, \quad F(1,231)=3.867, \quad F(1,252)=4.834, \quad F(1,252)=4.834$,

f.

$$
p=.036, \eta^{2}=.04 \quad p=.577, \eta^{2}=.00
$$

$p=.050, \eta^{2}=.02$

$p=.029, \eta^{2}=.02$

$p=.029, \eta^{2}=.02$

DASS-S-f. $\quad F(1,116)=7.919, \quad F(1,97)=1.582$,

$F(1,231)=8.426, \quad F(1,252)=7.006, \quad F(1,252)=7.006$,

$$
p=.006, \eta^{2}=.06
$$

$p=.212, \eta^{2}=.02$

$p=.004, \eta^{2}=.04$

$p=.009, \eta^{2}=.03$

$p=.027, \eta^{2}=.03$

SCAS-no

$t(147)=-1.580$,

$t(130)=-.106$,

$t(306)=-2.670$,

$t(352)=-3.434$,

$t(348)=-3.014$

social-m

$p=.116, r=.13$

$p=.916, r=.01$

$p=.008, r=.13$

$p=.001, r=.19$

$p=.003, r=.14$ 


$\begin{array}{llllll}\text { SCAS-no } & t(119)=-3.015, & t(96)=-2.733, & t(239)=-3.137, & t(264)=-3.598, & t(262)=-3.024 \\ \text { Social-f } & p=.003, r=.26 & p=.007, r=.27 & p=.002, r=.20 & p<.001, r=.20 & p=.003, r=.17 \\ \text { SCAS-no } & t(154)=-.310, & t(131)=-1.080, & t(323)=-2.316, & t(369)=-2.489, & t(365)=-2.569, \\ \text { social-c } & p=.757, r=.03 & p=.282, r=.09 & p=.021, r=.13 & p=.013, r=.14 & p=.011, r=.19\end{array}$

Note : SIAS = Social Interaction Anxiety Scale; SPS = Social Phobia Scale; DASS-D-m = DASS-Depression subscalemother report; DASS-A-m = DASS-Anxiety subscale-mother report; DASS-S-m = DASS-Stress subscale-mother report; DASS-D-f = DASS-Depression subscale-father report; DASS-A-f = DASS-Anxiety subscale-father report; DASS-S-f = DASS-Stress subscale-father report; SCAS-no social-m = Spence Children's Anxiety Scale excluding social phobia subscale-mother report; SCAS-no social-f = Spence Children's Anxiety Scale excluding social phobia subscale - father report; SCAS-no social-c = Spence Children's Anxiety Scale excluding social phobia subscale-child report. 